\title{
Clinical Impact of a Surgical Energy Device in Advanced Ovarian Cancer Surgery Including Bowel Resection
}

\author{
GIUSEPPE VIZZIELLI ${ }^{1}$, CARMINE CONTE $^{1}$, MASSIMO ROMANO $^{1}$, ANNA FAGOTTI $^{1}$, \\ BARBARA COSTANTINI ${ }^{1}$, CLAUDIO LODOLI ${ }^{2}$, SALVATORE GUELI ALLETTI $^{1}$, KHALED GABALLAH $^{1}$, \\ FABIO PACELLI ${ }^{2}$, ALFREDO ERCOLI $^{3}$, GIOVANNI SCAMBIA $^{1}$ and VALERIO GALLOTTA ${ }^{1}$ \\ Departments of ${ }^{1}$ Women's and Children's Health, and ${ }^{2}$ General Surgery, \\ Agostino Gemelli University Hospital, Catholic University, Rome, Italy; \\ ${ }^{3}$ Department of Obstetrics and Gynecology, University of Eastern Piedmont, Novara, Italy
}

\begin{abstract}
Aim: To evaluate the clinical impact of the use of the Caiman ${ }^{\circledR}$ articulating energy device in advanced ovarian cancer (AOC) including rectosigmoid resection [e.g. modified posterior exenteration (MPE)]. Patients and Methods: This was a prospective single-institution observational study with women undergoing MPE where all soft-tissue dissections and vessel ligations were performed using the Caiman ${ }^{\circledR}$ device. Intraoperative and postoperative surgical data were collected. Bladder function after nervesparing surgery was analyzed before and 6 months after surgery. Results: Forty patients were registered in the study. The median time for specimen removal using Caiman ${ }^{\circledR}$ was $86 \mathrm{~min}$ (range=70-120 $\mathrm{min}$ ). Major vessel ligation was successful in all patients with a median of a single (range =1-4) Caiman ${ }^{\circledR}$ application to seal major vessels. No intraoperative or postoperative complications or bladder dysfunctions associated with the use of Caiman ${ }^{\circledR}$ were noted. Conclusion: Caiman ${ }^{\circledR}$ can be safely used in AOC surgery and may save time through faster dissection. However, comparative studies with other energy devices are needed to confirm this finding.
\end{abstract}

The evolution of surgery has encouraged the use of new devices in abdominal soft-tissue dissection. Indeed, mesentery dissection and the separation of other soft tissues (e.g. the omentum) may take a considerable amount of time in terms of safe, rapid, and effective hemostasis. Recently,

This article is freely accessible online.

Correspondence to: Dr. Giuseppe Vizzielli, Division of Gynecologic Oncology, "Agostino Gemelli” Foundation University Hospital, Rome, Italy. Tel: +39 0630154979, Fax: +39 063052132, e-mail: giuseppevizzielli@yahoo.it; giuseppe.vizzielli@policlinicogemelli.it

Key Words: Ovarian cancer, energy device, surgery, Caiman ${ }^{\circledR}$. the American College of Surgeon and Society of American Gastrointestinal and Endoscopic Surgeons initiated the Fundamental Use of Surgical Energy program to develop training in energy device safety and optimal use (https://www.fuseprogram.org/).

A novel energy device, approved by the US Food and Drug Administration in March 2013, has been developed (Caiman ${ }^{\circledR}$; Aesculap AG, Tuttlingen, Germany) using advanced bipolar seal-and-cut technology for rapid, safe, and effective soft-tissue dissection, especially in oncological surgical procedures $(1,2)$.

Due to the anatomic proximity of the rectosigmoid colon to the female pelvic organs and its common involvement in advanced ovarian cancer (AOC), rectosigmoidal resection is frequently performed to achieve a complete cytoreduction (i.e. absent residual tumor, $\mathrm{RT}=0$ ) with acceptable morbidity and mortality rates (3-6). Moreover, bearing in mind that the autonomic nerves in the pelvis are crucial for successful urination, both radical hysterectomy and radical resection of the rectosigmoidal colon can impair them, often causing bladder dysfunction (7). At the time of the initiation of this study, there were no reports on Caiman ${ }^{\circledR}$ use in patients with AOC and its clinical impact regarding operative time, or intra- and postoperative complications. Thus, this prospective trial aimed to estimate the clinical performance of the Caiman ${ }^{\circledR}$ energy device during primary debulking surgery in AOC including rectosigmoid resection [namely modified posterior exenteration (MPE)].

\section{Patients and Methods}

This was a prospective single-Institution observational study approved by an Institutional Review Board (Prot. N. 25543/16, ClinicalTrials.gov identifier: NCT03219242). All women were enrolled between July 2016 and June 2017 at Agostino Gemelli University Hospital, Catholic University, Rome, Italy. Women above 18 years of age and with American Society of Anesthesiologists (ASA) class 1-2 undergoing MPE for AOC were included in the 
study. Patients with pelvic inflammatory disease and previous radiotherapy were excluded. We also excluded patients with chronic infections (inflammatory bowel disease), patients for whom electrosurgery was contraindicated, and pregnant patients.

Data were collected prospectively before, during, and after surgery. Documented end-points were dissection time (from the start of colon mobilization to specimen removal), operating time, the number of times Caiman ${ }^{\circledR}$ was taken out of the abdominal cavity, use of other energy devices, intra-operative complications (bleeding at the time of vessel ligation, visible thermal injury during surgery and injury of other organs), number of device applications needed to achieve vessel ligation, device technical problems, postoperative complications (postoperative bleeding, delayed thermal injuries, and other postoperative complications within 30 days), length of hospital stay, and mortality.

The co-primary end-points were intraoperative complications and the time for dissection of the soft tissues necessary for specimen removal during MPE, measured in minutes, from the start of colon mobilization to specimen removal from the abdominal cavity. The total surgical time was measured in minutes from the skin incision to the last stitch (skin to skin).

Furthermore, the clinical performance was measured regarding safety and effective division of the mesentery of the large bowel with its major vessels and separation of the omentum. We also measured the number of the applications needed to achieve adequate ligation and bleeding at the time of vessel ligation. Postoperatively, patients were assessed daily after surgery until discharge, at the first follow-up clinic visit (typically within the first 30 days following surgery) and once more at 30 days after surgery. For patients with difficulty in spontaneous voiding after surgery, intermittent catheterization was initiated to quantify the volume of postvoid residual urine (PVR). Self-intermittent catheterization was necessary in cases with voiding difficulty or PVR volume $>100 \mathrm{ml}$ at the time of discharge from the hospital. Bladder function was assessed before and at 3 and 6 months after surgery using the International Prostate Symptom Score (I-PSS) and the short-form version of the Urogenital Distress Inventory (UDI-6). The I-PSS questionnaire was originally developed to standardize the assessment of lower urinary tract symptoms (LUTS) in elderly men with benign prostatic hyperplasia. This questionnaire has been widely used to assess the severity and degree of symptoms caused by LUTS and the influence of LUTS on quality of life. It has been shown to be neither disease- nor sex-specific (8). The UDI-6 questionnaire has also been validated for evaluation of urinary incontinence in apparently healthy persons of both sexes (9). The I-PSS was useful for evaluating general bladder function in patients in whom MPE had been performed as part of cytoreductive surgery for gynecological cancer, whereas the UDI-6 was useful for evaluating recovery from severe bladder dysfunction and incontinence.

The I-PSS includes four items regarding voiding symptoms (incomplete emptying of the bladder, intermittency during urination, weak urinary stream, and straining) and three items regarding storage symptoms (daytime frequency, urgency, and nycturia). The seven questions of the I-PSS are scored on a scale from 0 to 5 points. The UDI-6 consists of six questions (comprising questions 1 and 2 about irritative symptoms, questions 3 and 4 about stress symptoms, and questions 5 and 6 about obstructive/discomfort symptoms) and is scored on a scale from 0 to 3 points. Patients with no symptoms score 0 on both these questionnaires; the maximum possible scores are 35 on the I-PSS and 18 on the UDI-6. Higher postoperative I-PSS and UDI6 scores compared with preoperative scores indicate an aggravated condition, whereas lower postoperative scores indicate improvement.
Equipment. The Caiman ${ }^{\circledR} 12$ articulating energy device $(12 \mathrm{~mm}$ diameter, $24 \mathrm{~cm}$ working length, PL730SU; Aesculap AG) was used in all cases. The instrument was cleared under $510(\mathrm{~K})$ approval (K130596) in March 2013 by the US FDA and it is in conformity with the requirements of the Medical Device Directive 93/42/EEC; currently it is used in standard surgical procedures at our Institution. The Caiman has a shaped jaw design with a wide opening aperture and an 80-degree distal articulated tip which results in simplified jaw positioning on the targeted tissue (Figure 1). It features a patented mechanism which is key to enabling high uniform tissue compression utilizing a very long jaw $(50 \mathrm{~mm})$, achieving potentially excellent vessel-sealing quality and avoiding tissue slippage.

Surgical procedures. All surgeons had completed at least 10 human surgical cases as the standard of care before participating in this study. All surgical procedures were performed under general anesthesia and according to the surgical standard of care (6). MPE according to Kato et al. (5) was completed in all 40 women with AOC. Preservation of the pelvic autonomic nerves on both sides was attempted whenever possible. However, a unilateral or bilateral sacrifice of the pelvic autonomic nerves was necessary in cases with tumor infiltration into the pelvic side-wall to achieve optimal cytoreduction and complete the surgical procedure safely. Soft-tissue dissection and all vessel ligations were performed using the Caiman ${ }^{\circledR}$ energy device. The surgical dissection approach, medial to lateral or lateral to medial, and the number of applications of Caiman ${ }^{\circledR}$ during vessel ligation were according to the individual surgeon's decision and preference. The ligation of ovarian pedicles, uterine arteries and parametria was documented in radical hysterectomy; the ligation of inferior mesenteric artery, left colic arteries, sigmoidal arteries, and the superior rectal arteries were documented in left colectomies or rectosigmoidal resection; the ligation of ileocolic, right colic, and middle colic arteries were documented in right colonic resections; the ligation of splenic pedicle was documented in splenectomy.

Statistical analysis. Descriptive analyses presenting the central tendency and dispersion of the data were performed. The baseline data [age, gender, ASA score, body mass index (BMI), prior surgery and preoperative diagnoses], intraoperative data (estimated blood loss, operative time, time to specimen removal, vascular ligation technique, number of applications, intra-operative bleeding, intraoperative complications, conversions, visible injuries from thermal spread and instrumental data), and postoperative complications (bleeding, infection, delayed thermal injury) are summarized with the median (range) or presented as frequencies and proportions of the population sample. For evaluation of urinary symptoms, ANOVA for repeated measures was used to analyze modifications of UDI-6 and I-PSS measures over time. Statistical analysis was performed with $\mathrm{NCSS}^{\circledR}$ statistical software, version 11.0 (Kaysville, UT, USA).

\section{Results}

In the study period, 40 women were enrolled. Clinical data are shown in Table I. Median age was 58 (range=35-75) years and BMI was 26 (range $=20-39) \mathrm{kg} / \mathrm{m}^{2}$. All patients had ovarian neoplasm as preoperative diagnosis and underwent elective surgery for MPE of their medical condition. The median ASA category was 1 with range 1-2 (Table I). The median surgical 


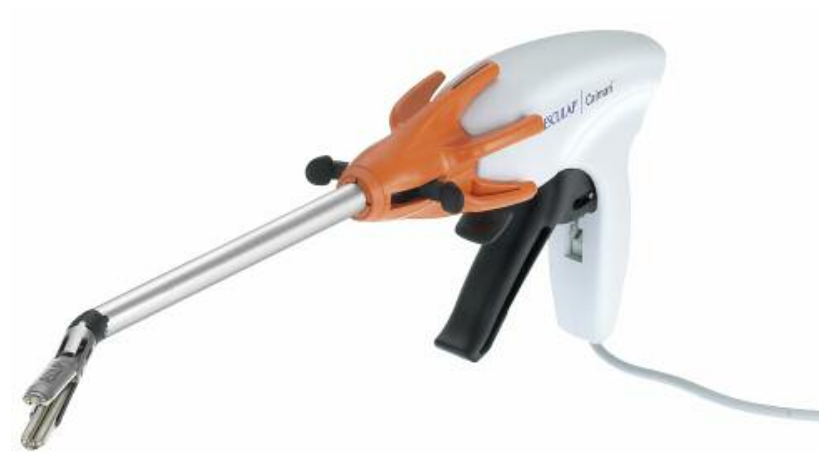

Figure 1. The Caiman ${ }^{\circledR}$ articulating energy device.

procedure time was 400 (range $=210-600)$ min and median time for specimen removal using the Caiman ${ }^{\circledR}$ device was 86 (range $=70-120)$ min. Major vessel ligation was successful in all patients. A median of one Caiman ${ }^{\circledR}$ application (range $=1$ 2) to seal the inferior mesenteric artery was required, as was for the sigmoidal artery. The ligation of superior rectal arteries with surrounding soft tissues required a median of two Caiman applications (range $=2-4$ ). The rest of the major arterial vessels (right colic, middle colic, left colic, and sigmoid arteries) required one application (range $=1-2$ ) s to achieve ligation. Figure 2 demonstrates vessel ligation and tissue dissection using the Caiman ${ }^{\circledR}$.

No intraoperative adverse events (bleeding complication, organ injuries, or thermal injuries) related to use of the Caiman ${ }^{\circledR}$ were noted in this study. It was not necessary in any case to take the Caiman ${ }^{\circledR}$ out of the abdominal cavity for tip clean-up (Table II). No technical malfunctions were noted. One patient $(2.5 \%)$ who underwent MPE with colorectal anastomosis and diverting ileostomy developed an anastomotic leak and abdominal abscess on postoperative day 6. The patient was treated surgically and recovered successfully. This complication was not related to use of the Caiman ${ }^{\circledR}$. There were no intraoperative or postoperative bleeding events, and no patients received blood transfusion while in hospital. There were no postoperative complications events related to use of Caiman ${ }^{\circledR}$. The postsurgical length of stay was a median of four days, with range 3-10 days. All patients completed 30-day postsurgical follow-up, and there was no mortality (Table III).

Sufficient micturition was observed in all patients in whom bilateral nerve-sparing MPE $(n=36)$ or unilateral nerve-sparing MPE $(n=4)$ was performed. No intermittent catheterization was required. Recovery of bladder function had occurred in all cases by 6 months after surgery and scores for voiding symptoms had decreased. However, since the results at 3 and 6 months were overlapping, we only considered the long-term results for calculation

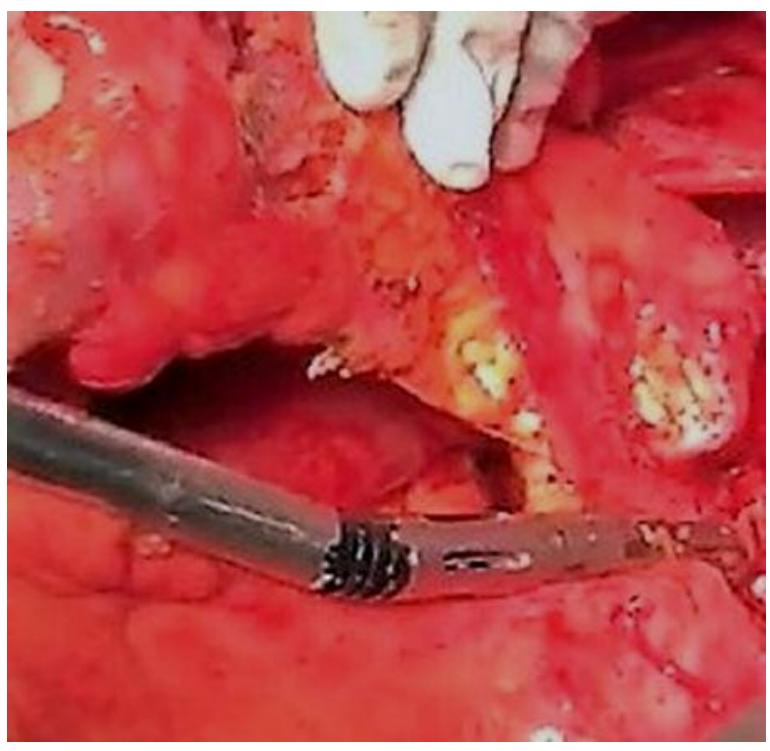

Figure 2. Caiman ${ }^{\circledR}$ used in sealing the inferior mesenteric artery.

Table I. Demographic characteristics and peri-operative data.

\begin{tabular}{lc}
\hline Variable & Value \\
\hline All cases (N) & 40 \\
Median age (range), years & $58(35-75)$ \\
Median BMI (range), $\mathrm{kg} / \mathrm{m}^{2}$ & $26(20-39)$ \\
Median ASA (range) & $1(1-2)$ \\
Previous caesarean section, n (\%) & $2(5 \%)$ \\
Previous abdominal surgery, n (\%)) & $19(47.5 \%)$ \\
PDS, n (\%) & $40(100 \%)$ \\
FIGO stage, n (\%) & $38(95.0 \%)$ \\
III & $2(5.0 \%)$ \\
IV & \\
Residual tumor, n (\%) & $38(95.0 \%)$ \\
Absent & $2(5.0 \%)$ \\
$>1 \mathrm{~cm}$ &
\end{tabular}

ASA: American Society of Anesthesiologists; BMI: body mass index; PDS: primary debulking surgery; FIGO: International Federation of Gynecology and Obstetrics.

(Figure 3). The most frequent postoperative complaint was a weak urinary stream, which was reported as a new complaint in 12 patients $(30 \%)$ and as a persistent complaint from the preoperative period in five $(12.5 \%)$ women. Preoperatively, 30 patients $(75 \%)$ had complained of storage symptoms to some extent, especially an increased frequency of micturition; however, all these complaints tended to have been resolved by 6 months postoperatively (Figure 3). 
Table II. Intraoperative data.

\begin{tabular}{|c|c|}
\hline Variable & Value \\
\hline Median operative time (range), min & $400(210-600)$ \\
\hline Median time to specimen removal (range), min & $86(70-120)$ \\
\hline \multirow{2}{*}{\multicolumn{2}{|c|}{$\begin{array}{l}\text { Median no. of Caiman applications } \\
\text { to seal vessels, } n \text { (range) }\end{array}$}} \\
\hline & \\
\hline Uterine artery & $1(1-2)$ \\
\hline Ovarian pedicle & $1(1-2)$ \\
\hline IMA & $1(1-2)$ \\
\hline Right colic & $1(1-2)$ \\
\hline Middle colic & $1(1-2)$ \\
\hline Left colic & $1(1-2)$ \\
\hline Sigmoid arteries & $1(1-2)$ \\
\hline Superior rectal arteries & $2(2-4)$ \\
\hline Splenic pedicle & $2(1-3)$ \\
\hline Bleeding at vessel ligation, n (\%) & 0 \\
\hline Intraoperative thermal injury, $\mathrm{n}(\%)$ & 0 \\
\hline Median estimated blood loss(range), $\mathrm{ml}$ & $600(50-2,000)$ \\
\hline Intraoperative blood transfusion, n (\%) & $1(2.5 \%)$ \\
\hline \multicolumn{2}{|l|}{ Surgical procedures, n (\%) } \\
\hline Radical hysterectomy & $40(100 \%)$ \\
\hline Bilateral adnexectomy & $40(100 \%)$ \\
\hline Omentectomy & $40(100 \%)$ \\
\hline Recto-sigmoid resection & $40(100 \%)$ \\
\hline Ileum resection & $3(7.5 \%)$ \\
\hline Protective ileostomy & $13(32.5 \%)$ \\
\hline Diaphragm stripping & $20(50.0 \%)$ \\
\hline Splenectomy & $9(22.5 \%)$ \\
\hline Liver resection & $4(10.0 \%)$ \\
\hline Appendectomy & $9(22.5 \%)$ \\
\hline Pelvic lymphadenectomy & $16(40 \%)$ \\
\hline Aortic lymphadenectomy & $10(25.0 \%)$ \\
\hline Celiac trunk lymphadenectomy & $7(17.5 \%)$ \\
\hline
\end{tabular}

IMA: Inferior mesenteric artery.

\section{Discussion}

The new surgical boundaries have stimulated the use of advanced technologies and development of new surgical devices. Safe hemostasis and mesenteric tissue dissection are fundamental to any abdominal surgical procedure. Operative time along with other intraoperative variables is of considerable importance as it greatly influences the costeffectiveness of any surgical procedure. Currently, open, as well as advanced laparoscopic procedures, still mainly use mechanical (suture, clips, or staples) or energy surgical instruments to achieve adequate hemostasis during tissue dissection and vessel ligation.

This is the first study, to our knowledge, which deeply analyzed the clinical performance of Caiman ${ }^{\circledR}$ in a specific subset of patients requiring at least an MPE. In this study, we used Caiman ${ }^{\circledR}$ for mesentery dissection, omental dissection, splenic flexure or hepatic flexure take down and
Table III. Postoperative data.

\begin{tabular}{lc}
\hline Variable & Value \\
\hline Intraoperative complications, n (\%)* & $5(12.5)$ \\
Hepatic vein injury & $1(2.5)$ \\
Bladder lesion & $3(7.5)$ \\
Hemorrhage & $1(2.5)$ \\
Post-operative complications, n (\%)* & $5(16.6)$ \\
Grade 2 & $3(7.5)$ \\
Acute kidney failure & $1(2.5)$ \\
Hepatopathy & $1(2.5)$ \\
Wound infection & $2(5.0)$ \\
Bowel's occlusion & $1(2.5)$ \\
Grade 3 & $2(5)$ \\
Fever and pleural effusion & $1(2.5)$ \\
Anemia (<8 g/dl) & $1(2.5)$ \\
Anastomotic leak & $1(2.5)$ \\
Postoperative complications related to & \\
Caiman ${ }^{\circledR *}$ (including delayed thermal injuries), n (\%) & 0 \\
Postoperative bleeding, n (\%) & 0 \\
Postop anticoagulant prophylaxis, n (\%) & 40 \\
Median hospital stay (range), days & $4(3-10)$ \\
Mortality, n (\%) & 0 \\
Median time to chemotherapy (range), days & $40(30-76)$ \\
\hline
\end{tabular}

*According to Clavien-Dindo classification (10).

vessel ligation, uterine artery, and pedicle vessel ligation. Our mean time from colon mobilization to specimen removal (uterus and recto-sigma) was 80 (70-120) min without hemostasis failure while ligating major vessels using the Caiman. Although no other direct or indirect comparison with other surgical devices using the same energy setting (e.g. Ligasure ${ }^{\circledR}$ ) is available, the jaw length and its articulation would allow considerable time to be saved. Indeed, bearing in mind the potential bias of a singleinstitution experience and a possible incorrect match of clinical cases, in our previous published experience with a similar subset of patients (7), we registered a longer operative time (median=451 min), thus suggesting faster dissection of soft tissue using Caiman ${ }^{\circledR}$.

Moreover, in devices using advanced bipolar energy, the jaw becomes very hot, and care needs to be exercised to avoid touching vital structures as thermal injury may occur. Surprisingly, few data are present about the impact on potential neurological damage from energy devices to autonomic nerves, in particular voice quality after thyroidectomy (8). However, we did not have any intraoperative or postoperative thermal injuries as shown by vesical post-surgical functioning.

In this experience, all patients were discharged with the recovery of spontaneous voiding and without the need for selfcatheterization. Concerning the extent of hysterectomy during 


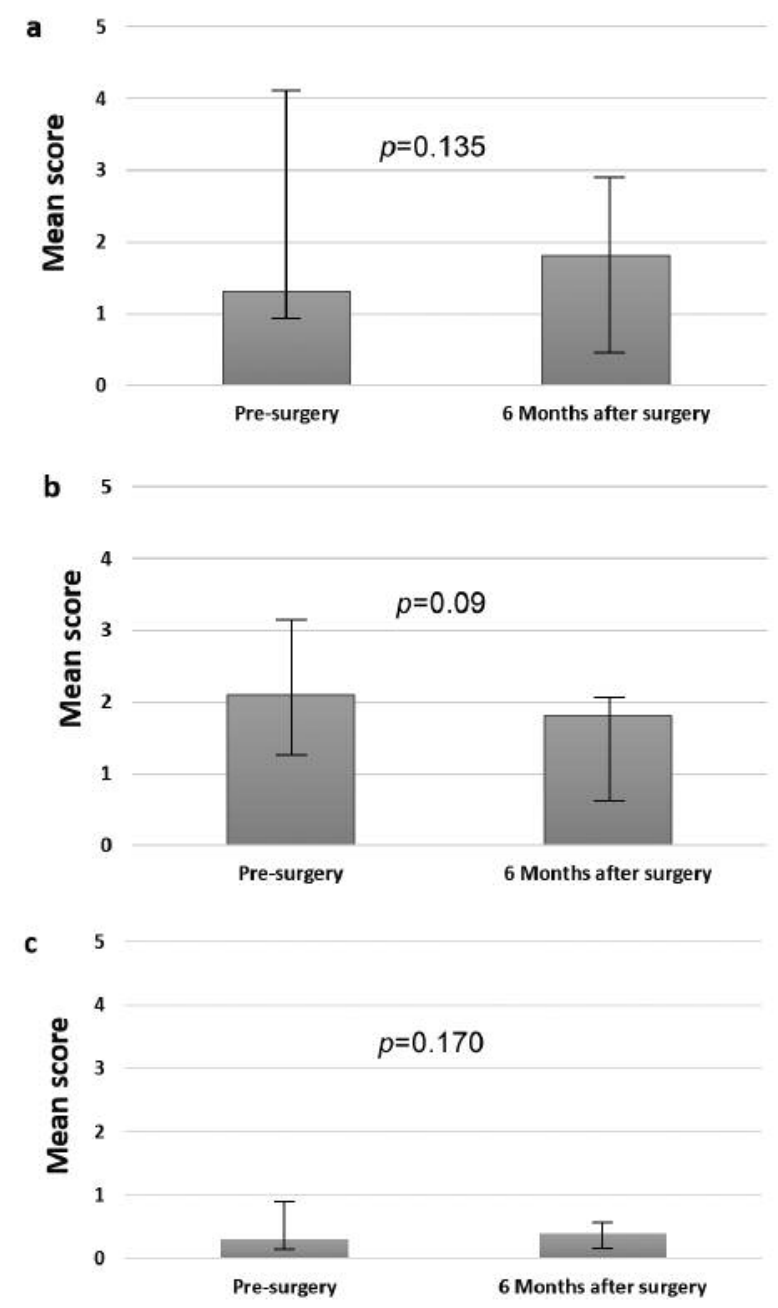

Figure 3. Symptoms and bladder function before and 6 months after modified posterior exenteration using the International Prostate Symptom Score (I-PSS) and the short-form version of the Urogenital Distress Inventory (UDI-6) questionnaires. The data represent mean values of the sum of both scores. a: Pre-and postoperative scores for voiding symptoms. $b$ : Pre- and postoperative scores for storage symptoms. c: Pre- and postoperative scores for stress symptoms. Statistical comparison of scores at different time points was performed using the ANOVA test.

nerve-sparing MPE, the spread of the disease usually necessitates mobilization of the ureters away from the tumorinfiltrated peritoneum, allowing uterine vessel ligation, as described in the procedure of a type B hysterectomy (9). However, the use of Caiman ${ }^{\circledR}$ in MPE does not appear to cause neurological damage, confirming that the outer jaw maintains low temperatures (average $66^{\circ} \mathrm{C}$, as declared by Aesculap) to protect adjacent tissue even after consecutive seals.

Bladder function was assessed before and 6 months after surgery. Thirty (75\%) women complained of storage symptoms pre-operatively: this symptom may have been associated with smaller bladder capacity caused by compression from the pelvic tumor. After cytoreductive surgery, this pressure disappeared, and this symptom tended to be resolved. In this study, the most frequent complaint after surgery was a weak urinary stream. This complaint arose from the patients' inability to maintain adequate detrusor contraction or relax the urethra. However, in this study, voiding symptoms (including weak urinary stream) tended to be resolved 6 months after surgery. Differences in storage and stress symptoms (stress incontinence) 6 months after surgery were not statistically significant. Considering that about $15 \%$ of normal healthy women will report regular urinary incontinence (10), although these results could due to the small sample size, these data indirectly show that lateral thermic damage of Caiman ${ }^{\circledR}$ is limited. Thus, the conditions causing any urinary symptoms may include reversible factors, such as edema and soft-tissue contusion, without injury to the hypogastric nerve.

Even though prospective, our study is not without limitations. Indeed, since the study was a single-institutional study with a small sample size using the Caiman ${ }^{\circledR}$ in the MPE with highly experienced surgeons, the results may not be generalizable for other institutions. Moreover, although the present study was not designed with cost-effect intent, it might be interesting in the near future to compare costs of Caiman ${ }^{\circledR}$ or other similar energy devices and reduction in operative time in this specific subset of patients.

However, whilst waiting for further comparative studies with other energy devices, Caiman ${ }^{\circledR}$ can be effectively used as a faster tissue dissector and safer vessel ligator in patients undergoing MPE.

\section{Competing Interests}

The Authors declare that they have no competing interests in regard to this study.

\section{Acknowledgements}

This study was investigator-initiated and was partially funded by a research grant from Aesculap AG, Tuttlingen, Germany, who also provided the devices for the study free of charge.

\section{References}

1 Berber E, Akyuz M, Aucejo F, Aliyev S, Aksoy E, Birsen O and Taskin E: Initial experience with a new articulating energy device for laparoscopic liver resection. Surg Endosc 28(3): 974978, 2014.

2 Cassini D, Miccini M, Gregori M, Manoochehri F and Baldazzi G: Impact of radiofrequency energy on intraoperative outcomes of laparoscopic colectomy for cancer in obese patients. Updates Surg 69(4): 471-477, 2017. 
3 Aletti GD, Podratz KC, Jones MB and Cliby WA: Role of rectosigmoidectomy and stripping of pelvic peritoneum in outcomes of patients with advanced ovarian cancer. J Am Coll Surg 203(4): 521-526, 2006.

4 Gallotta V, Fanfani F, Vizzielli G, Panico G, Rossitto C, Gagliardi ML, Margariti PA, Salerno MG, Zannoni GF, Pacelli F, Scambia G and Fagotti A: Douglas peritonectomy compared to recto-sigmoid resection in optimally cytoreduced advanced ovarian cancer patients: analysis of morbidity and oncological outcome. Eur J Surg Oncol 37(12): 1085-1092, 2011.

5 Vizzielli G, Costantini B, Tortorella L, Petrillo M, Fanfani F, Chiantera V, Ercoli A, Iodice R, Scambia G and Fagotti A: Influence of intraperitoneal dissemination assessed by laparoscopy on prognosis of advanced ovarian cancer: an exploratory analysis of a single-institution experience. Ann Surg Oncol 21(12): 3970-3977, 2014.

6 Vizzielli G, Costantini B, Tortorella L, Pitruzzella I, Gallotta V, Fanfani F, Gueli Alletti S, Cosentino F, Nero C, Scambia G and Fagotti A: A laparoscopic risk-adjusted model to predict major complications after primary debulking surgery in ovarian cancer: A single-institution assessment. Gynecol Oncol 142(1): 19-24, 2016

7 Kato K, Tate S, Nishikimi K and Shozu M: Bladder function after modified posterior exenteration for primary gynecological cancer. Gynecol Oncol 129(1): 229-233, 2013.

8 Chancellor MB and Rivas DA: American Urological Association symptom index for women with voiding symptoms: lack of index specificity for benign prostate hyperplasia. J Urol 150(5Pt2): 1706-1709, 1993.
9 Uebersax JS, Wyman JF, Shumaker SA, McClish DK and Fantl JA: Short forms to assess life quality and symptom distress for urinary incontinence in women: the Incontinence Impact Questionnaire and the Urogenital Distress Inventory. Continence Program for Women Research Group. Neurourol Urodyn 14(2): 131-139, 1995.

10 Clavien PA, Barkun J, de Oliveira ML, Vauthey JN, Dindo D, Schulick RD, de Santibañes E, Pekolj J, Slankamenac K, Bassi C, Graf R, Vonlanthen R, Padbury R, Cameron JL and Makuuchi $\mathrm{M}$ : The Clavien-Dindo classification of surgical complications: five-year experience. Ann Surg 250(2): 187-196, 2009.

11 Uludag SS, Teksoz S, Arikan AE, Tarhan O, Yener HM, Ozcan M, Liddy W and Randolph GW: Effect of energy-based devices on voice quality after total thyroidectomy. Eur Arch Otorhinolaryngol 274(5): 2295-2302, 2017,

12 Fujii S, Takakura K, Matsumura N, Higuchi T, Yura S, Mandai $\mathrm{M}$, Baba $\mathrm{T}$ and Yoshioka S: Anatomic identification and functional outcomes of the nerve sparing Okabayashi radical hysterectomy. Gynecol Oncol 107(1): 4-13, 2007.

13 Jackson KS and Naik R: Pelvic floor dysfunction and radical hysterectomy. Int J Gynecol Cancer 16(1): 354-363, 2006. 